\title{
Hyperglycemia Normalizes Insulin-stimulated Skeletal Muscle Glucose Oxidation and Storage in Noninsulin-dependent Diabetes Mellitus
}

\author{
David E. Kelley and Lawrence J. Mandarino \\ Departments of Medicine, Ophthalmology, and Physiology, University of Pittsburgh, The Eye and Ear Institute of Pittsburgh, \\ and the Department of Veterans Affairs Medical Center, Pittsburgh, Pennsylvania 15213
}

\begin{abstract}
The diminished ability of insulin to promote glucose disposal and storage in muscle has been ascribed to impaired activation of glycogen synthase (GS). It is possible that decreased glucose storage could occur as a consequence of decreased glucose uptake, and that GS is impaired secondarily. Muscle glucose uptake in 15 diabetic subjects was matched to 15 nondiabetic subjects by maintaining fasting hyperglycemia during infusion of insulin. Leg muscle glucose uptake, glucose oxidation (local indirect calorimetry), release of glycolytic products, and muscle glucose storage, as well as muscle GS and pyruvate dehydrogenase (PDH) were determined before and during insulin infusion. Basal leg glucose oxidation and PDH were increased in the diabetics. Insulin-stimulated leg glucose uptake in the diabetics $(8.05 \pm 1.41 \mu \mathrm{mol} /[\mathrm{min} \cdot 100 \mathrm{ml}$ leg tissue]) did not differ from controls (5.64 \pm 0.37$)$. Insulin-stimulated leg glucose oxidation, nonoxidized glycolysis, and glucose storage $(2.48 \pm 0.27,0.68 \pm 0.15$, and $5.04 \pm 1.34 \mu \mathrm{mol} /[\mathrm{min} \cdot 100 \mathrm{ml}]$, respectively) were not different from controls $(2.18 \pm 0.12$, $0.62 \pm 0.16$, and $2.83 \pm 0.31$ ). PDH and GS in noninsulin-dependent diabetes mellitus (NIDDM) were also normal during insulin infusion. When diabetics were restudied after being rendered euglycemic by overnight insulin infusion, GS and PDH were reduced compared with hyperglycemia. Thus, fasting hyperglycemia is sufficient to normalize insulin-stimulated muscle glucose uptake in NIDDM, and glucose is distributed normally to glycogenesis and glucose oxidation, possibly by normalization of GS and PDH. (J. Clin. Invest. 1990. 86:1999-2007.) Key words: noninsulin-dependent diabetes mellitus - muscle glucose metabolism • glycogen synthase • pyruvate dehydrogenase
\end{abstract}

\section{Introduction}

Skeletal muscle is thought to be a major site of the insulin resistance characteristic of noninsulin-dependent diabetes mellitus (NIDDM) ${ }^{1}(1-4)$. When subjects with NIDDM are

Address correspondence and reprint requests to Dr. Lawrence J. Mandarino, The Eye and Ear Institute of Pittsburgh, 203 Lothrop Street, Pittsburgh, PA 15213.

Received for publication 20 October 1990 and in revised form 8 August 1990.

1. Abbreviations used in this paper: FV, femoral venous; GS, glycogen synthase; G6P, glucose 6 phosphate; NIDDM, noninsulin-dependent diabetes mellitus; $\mathrm{PDH}$, pyruvate dehydrogenase; $\mathrm{PDH}_{\mathrm{a}}, \mathrm{PDH}_{\mathrm{FV}}$, $\mathrm{PDH}_{\mathrm{t}}$, active, fractional velocity, total PDH.

J. Clin. Invest.

(C) The American Society for Clinical Investigation, Inc.

0021-9738/90/12/1999/09 \$2.00

Volume 86, December 1990, 1999-2007 rendered euglycemic by means of an insulin infusion, the deficit in insulin-stimulated systemic glucose disposal can largely be accounted for by decreased glucose storage in muscle (5). Because impaired insulin activation of muscle glycogen synthase is correlated with impaired glucose storage, it has been suggested that an intra-cellular defect is responsible for decreased glucose disposal (5). However, it is possible that decreased glucose storage could occur solely as a consequence of decreased glucose uptake, and that impaired activation of glycogen synthase is a secondary effect.

Distinguishing between these possibilities is critical to understanding the biochemical mechanism(s) responsible for skeletal muscle insulin resistance. One way of distinguishing between the two would be to match rates of muscle glucose uptake in NIDDM and nondiabetic subjects at equivalent hyperinsulinemia and assess oxidative and nonoxidative muscle glucose metabolism. Revers et al. (6) found that maintaining fasting hyperglycemia in NIDDM subjects during infusion of insulin was sufficient to match rates of systemic glucose disposal to those obtained in euglycemic nondiabetics. This experimental approach would be useful to probe the regulation of intracellular muscle glucose metabolism. Thorburn et al. (7) adjusted hyperglycemia in NIDDM subjects to obtain equivalent systemic glucose disposal to euglycemic controls (at matched insulin infusions), and found reduced systemic glucose oxidation and increased plasma lactate concentrations. These investigators inferred that there was a higher rate of muscle Cori cycle activity in NIDDM. However, under those experimental conditions these abnormalities cannot be attributed solely to skeletal muscle, because the extreme hyperglycemia induced in that study ( $\sim 20 \mathrm{mmol} /$ liter) would increase lactate production by other tissues such as liver (8-17). In another study, Shulman et al. (18), using nuclear magnetic resonance techniques, found that during hyperglycemia in NIDDM the effects of insulin resistance in muscle are accounted for, nearly entirely, by impaired glycogen formation. However, the activity of muscle glycogen synthase, muscle glucose uptake, and lactate release were not determined in that study, leaving the biochemical mechanism of insulin resistance unknown.

These studies were undertaken to resolve the controversy of which metabolic pathways within skeletal muscle are affected by insulin resistance in NIDDM and, more specifically, to determine whether or not defects in intracellular glucose metabolism occur independently of glucose uptake. In order to more directly address these questions in skeletal muscle, limb balance rather than systemic techniques were used to estimate muscle glucose uptake and metabolism.

The limb balance technique is a direct in vivo method for assessment of glucose metabolism across a large bed of muscle, and has been used to specifically measure glucose uptake (8, $11,19)$, nonoxidized glycolysis (release of lactate) (20), and glucose oxidation $(21,22)$ (net indirect calorimetry based on 
gas exchange across the limb). The subtraction of the latter two pathways from glucose uptake provides an estimate of muscle glucose storage (22). The limb balance method provides direct data on muscle metabolism which cannot be obtained with studies of systemic glucose metabolism. Additionally, enzyme activities in biopsies of this muscle bed can be directly related to flux through the various pathways of glucose metabolism.

Our findings demonstrate that, in NIDDM, the fasting level of hyperglycemia is sufficient to normalize muscle glucose uptake during an insulin infusion. These normal rates of insulin-stimulated glucose uptake allow glucose storage, oxidation, and nonoxidized glycolysis to proceed at normal rates, which suggests that the site of muscle insulin resistance in NIDDM may be proximal to all these pathways. However, at hyperglycemia, insulin-stimulated muscle glycogen synthase (GS) and pyruvate dehydrogenase (PDH) activities were normalized in NIDDM, indicating that regulation of intracellular pathways of glucose metabolism may also be partially responsible for normalization of muscle glucose storage and oxidation. Finally, the finding of increased basal muscle glucose oxidation and PDH activity provides evidence that defects in basal muscle metabolism may contribute to systemic basal metabolic abnormalities in NIDDM.

\section{Methods}

Subjects (Table I). The studies were approved by the Institutional Review Board of the University of Pittsburgh School of Medicine and The Eye and Ear Institute of Pittsburgh, and informed written consent was obtained from each subject. The clinical characteristics of each subject are shown in Table $I$. All of the nondiabetic volunteers had normal glucose tolerance, as determined with a $1 \mathrm{~g} / \mathrm{kg}$ (maximum $75 \mathrm{~g}$ ) $2 \mathrm{~h}$ oral glucose tolerance test (23). 14 of the 15 subjects with NIDDM were being treated with oral hypoglycemic agents that were discontinued at least $2 \mathrm{wk}$ before the study. One of the diabetics had been treated by diet alone, and none of these subjects had been treated with insulin. Subjects were instructed to consume a diet containing at least $200 \mathrm{~g}$ of carbohydrate per day for the $3 \mathrm{~d}$ preceding admission and to not exercise on the day before the study. Body fat percentages were determined using bio-impedance (24).

Study design. Subjects were admitted to the University of Pittsburgh General Clinical Research Center on the evening before the study. They were fed a $10 \mathrm{kcal} / \mathrm{kg}$ evening meal ( $50 \%$ carbohydrate, $35 \%$ protein, and $15 \%$ fat) at 6 p.m., and fasted overnight. In the morning, catheters were placed in an antecubital vein for infusion of glucose and insulin, and a radial artery and a femoral vein for blood sampling. After an additional $90 \mathrm{~min}$, simultaneous arterial and

Table I. Clinical Characteristics of the Subjects

\begin{tabular}{lrrrrrr}
\hline & Age & BMI & $\begin{array}{c}\text { Body fat } \\
\text { (percent } \\
\text { of weight) }\end{array}$ & $\begin{array}{c}\text { Waist to } \\
\text { hip ratio }\end{array}$ & $\begin{array}{c}\text { Blood } \\
\text { glucose }\end{array}$ & Plasma IRI \\
\hline & $y r$ & $k g / m^{2}$ & & & mmol/liter & $m$ mU/liter \\
NIDDM & & & & & & \\
Mean & 58 & 28.5 & 24 & $0.98^{*}$ & $11.0^{\ddagger}$ & 12.8 \\
SEM & 2 & 2.0 & 2 & 0.01 & 0.6 & 1.5 \\
Controls & & & & & & \\
Mean & 54 & 27.1 & 19 & 0.93 & 4.88 & 9.6 \\
SEM & 2 & 1.0 & 2 & 0.01 & 0.10 & 0.8 \\
\hline
\end{tabular}

${ }^{*} P<0.05$ vs. controls; ${ }^{\ddagger} P<0.001$ vs. controls. venous blood samples were obtained for $30 \mathrm{~min}$ at 10 -min intervals for glucose, lactate, and alanine, and at 5-min intervals for $\mathrm{O}_{2}$ and $\mathrm{CO}_{2}$. Blood flow to the thigh was measured using impedance plethysmography (BIA II; BioMed Instruments Inc., La Jolla, CA). After the period of basal determinations, a percutaneous needle muscle biopsy was obtained from the vastus lateralis muscle under local superficial anesthesia ( $1 \%$ xylocaine without epinephrine). The biopsy was performed in the opposite thigh to that with the femoral vein catheter. The muscle sample was frozen in liquid nitrogen within $15 \mathrm{~s}$ for later determination of GS and PDH activity.

Immediately after the biopsy, a primed, continuous infusion of insulin (U-100 Humulin R; Eli Lilly and Co., Indianapolis, IN) was administered at $40 \mathrm{mU} /\left(\mathrm{m}^{2} \cdot \mathrm{min}\right)$ for $240 \mathrm{~min}$. Whole blood arterial glucose was determined every 5 min throughout the insulin infusion. In the diabetic subjects, arterial glucose was maintained at the individual's level of fasting hyperglycemia, and in nondiabetic subjects euglycemia was maintained with a variable infusion of $50 \%$ dextrose. During the insulin infusion, arterial and/or venous blood was obtained every $30 \mathrm{~min}$ for glucose, lactate, alanine, free fatty acid (FFA), and insulin. During the final $30 \mathrm{~min}$ of the insulin infusion, (210-240 min) simultaneous arterial and venous samples were obtained at 10-min intervals for glucose, lactate, alanine, FFA, and insulin, and every 5 min for $\mathrm{O}_{2}$ and $\mathrm{CO}_{2}$. After blood sampling was concluded but before stopping infusion of insulin, a second muscle biopsy was obtained from the vastus lateralis at a site $\sim 3 \mathrm{~cm}$ distal to the first biopsy. Patients remained supine throughout the study.

In four of the subjects with NIDDM, another study was conducted on a separate day. The subjects were admitted to the General Clinical Research Center in the afternoon on the day before the study and fed a standard dinner. A slow, intravenous infusion of insulin was then begun at a rate of $4-12 \mathrm{mU} /\left(\mathrm{m}^{2} \cdot \mathrm{min}\right)$ and continued overnight. The plasma glucose concentration was measured hourly overnight, and the insulin infusion was adjusted so as to achieve euglycemia. The next morning, while the overnight insulin infusion was still running, a biopsy of the vastus lateralis muscle was performed as described above. The insulin infusion was then increased to $40 \mathrm{mU} /\left(\mathrm{m}^{2} \cdot \mathrm{min}\right)$ and the plasma glucose was maintained at euglycemia $(5.3 \pm 0.2 \mathrm{mmol} / \mathrm{liter})$ by infusion of exogenous glucose. After $4 \mathrm{~h}$, a second muscle biopsy was taken and the insulin infusion was stopped. Biopsies were assayed for glycogen synthase and PDH activities.

Leg indirect calorimetry. During the $30-\mathrm{min}$ basal period and during the final $\mathbf{3 0} \mathrm{min}$ of the insulin infusion, simultaneous arterial and femoral venous blood samples were collected at 5-min intervals for measurement of $\mathrm{O}_{2}$ and $\mathrm{CO}_{2}$ content. These repetitive blood gas samples were drawn into heparinized syringes, immersed in ice, and analyzed within $5 \mathrm{~min}$. Plasma $\mathrm{CO}_{2}$ content was calculated from measured $\mathrm{CO}_{2}$ tension and $\mathrm{pH}$ (System $1304 \mathrm{pH} / \mathrm{Blood}$ Gas Analyzer; Allied Instrumentation Laboratory, Lexington, MA) using established equations and a solubility constant of $\mathbf{0 . 0 3 0 7}$. The blood gas analyzer was calibrated with a quantitative gasometric chemical technique. The accuracy of the equipment is $0.1 \mathrm{mmol} /$ liter for $\mathrm{CO}_{2}$. Plasma $\mathrm{CO}_{2}$ content was adjusted to whole blood $\mathrm{CO}_{2}$ content based on hemoglobin content, saturation, and $\mathrm{pH}$ using an empirically derived regression equation (25). This equation gives values of whole blood $\mathrm{CO}_{2}$ content that are in close agreement with determination of blood $\mathrm{CO}_{2}$ content by the Van Slyke method. A comparative advantage of the automated equipment used in this study over a Van Slyke apparatus is that six samples can be analyzed in approximately the time required to perform a single Van Slyke determination. A co-oximeter (IL282 Co-Oximeter System; Allied Instrument Laboratory) was used to measure hemoglobin content and oxygen saturation. $\mathrm{O}_{2}$ content was calculated from the hemoglobin content and percent saturation, using a constant of 1.34 . The accuracy of this equipment is $0.3 \mathrm{mmol} /$ liter for $\mathrm{O}_{2}$ content.

The basal and clamp arterial and venous blood $\mathrm{CO}_{2}$ and $\mathrm{O}_{2}$ contents were estimated as the mean of six respective determinations in each period. The coefficient of variation was calculated for each individual, and the mean intrasubject coefficient of variation was $\sim 1 \%$ for 
arterial $\mathrm{CO}_{2}$, femoral venous $\mathrm{CO}_{2}$, and arterial $\mathrm{O}_{2}$, and $4 \%$ for femoral venous $\mathrm{O}_{2}$ content.

Leg $\mathrm{O}_{2}$ consumption $\left(\mathrm{VO}_{2}\right)$ and $\mathrm{CO}_{2}$ production $\left(\mathrm{VCO}_{2}\right)$ were calculated as the product of the arteriovenous difference and leg blood flow. Rates of leg carbohydrate and lipid oxidation were calculated using the equations of Frayn (26), employing a constant for limb protein oxidation of $85 \mathrm{nmol} /(\mathrm{min} \cdot 100 \mathrm{ml}$ tissue), as kindly suggested by E. Ferrannini (personal communication), based on previous studies of muscle protein oxidation (27).

Analysis. Whole blood glucose was measured with a glucose analyzer (Yellow Springs Instrument Co., Yellow Springs, OH). Lactate and alanine determinations were made using microfluorometric assays $(28,29)$ performed on extracts of whole blood samples which had been immediately deproteinized with an equal volume of chilled $7 \%$ perchloric acid at the bedside. The supernatant was separated and stored at $-70^{\circ} \mathrm{C}$. Arterial plasma insulin was assayed by the method of Herbert et al. (30). Plasma FFA was measured enzymatically on arteria plasma samples using a commercial kit (NEFA C; Wako Pure Chemical Industries, Ltd., Osaka, Japan).

$P D H$ and GS activities. Assays of skeletal muscle PDH activity and GS activity were performed as previously described (31). PDH was assayed in the presence of fluoride with $50 \mu \mathrm{M}$ magnesium to measure active (PDA $\mathrm{a}_{\mathrm{a}}$, and in the absence of fluoride with $10 \mathrm{mM}$ magnesium to measure total $\mathrm{PDH}$ activity $\left(\mathrm{PDH}_{\mathrm{t}}\right)$. The pyruvate concentration in both cases was $1 \mathrm{mmol} /$ liter. The fractional velocity of $\mathrm{PDH}\left(\mathrm{PDH}_{\mathrm{Fv}}\right)$ is defined as $\mathrm{PDH}_{\mathrm{a}} / \mathrm{PDH}_{\mathrm{t}}$. GS was assayed in the presence of 0.1 or 10 $\mathrm{mmol} /$ liter glucose 6-phosphate (G6P) and $0.3 \mathrm{mmol} /$ liter UDPG. $\mathrm{GS}_{\mathrm{Fv}}$ is defined as the activity of GS assayed at $0.1 \mathrm{mmol} / \mathrm{liter} \mathrm{G} 6 \mathrm{P}$ divided by the activity of the enzyme assayed at $10 \mathrm{mmol} /$ liter G6P.

Calculations. Glucose, lactate, alanine, $\mathrm{O}_{2}$, and $\mathrm{CO}_{2}$ balance across the leg were calculated as the product of the arterio-venous concentration difference and blood flow and are expressed in units of $\mu \mathrm{mol} /(\mathrm{min} \cdot 100 \mathrm{ml}$ leg tissue). Leg glucose clearance was calculated by dividing leg glucose uptake by arterial glucose concentration.

Net leg glucose storage was calculated as the difference between glucose uptake and the sum of glucose oxidation and release of glycolytic products. This estimate of net storage can be positive or negative. If positive, it was interpreted as net glycogen synthesis, while if negative, as net glycogenolysis. When combined as a measure of release of glycolytic products, net leg lactate and alanine release was expressed in terms of glucose equivalents.

Statistics. Data are expressed as mean \pm SEM. Statistical comparisons were made using paired or unpaired $t$ tests, where appropriate, using a 0.05 significance level. All correlation analyses were performed by parametric methods (Pearson's $r$ ). Statistical analyses were performed using RS/1 (BBN Software, Cambridge, MA).

\section{Results}

Clinical characteristics (Table I). The diabetic and nondiabetic subjects were matched for age, body mass index (BMI), and percentage body fat, although the diabetics had a higher waist to hip ration. All subjects were male. The groups were moderately obese, as indicated by the mean BMIs, which is characteristic of the population of patients with NIDDM. Fasting plasma glucose ranged from 7.1 to $14.9 \mathrm{mmol} / \mathrm{liter}$ in the NIDDM subjects. Each control subject had normal glucose tolerance as determined with a $75 \mathrm{~g}$ oral glucose tolerance test; the mean plasma glucose values were $5.15 \pm 0.12$ at $0 \mathrm{~min}$, $9.37 \pm 0.39$ at $60 \mathrm{~min}$ and $6.56 \pm 0.36 \mathrm{mmol} / \mathrm{liter}$ at $120 \mathrm{~min}$.

Glucose clamp. In the postabsorptive state, blood glucose was $11.01 \pm 0.59 \mathrm{mmol} / \mathrm{liter}$ in NIDDM subjects and was kept constant during insulin infusion $(10.96 \pm 0.54 \mathrm{mmol} /$ liter $)$ by exogenous glucose infusion. In controls, blood glucose was $4.88 \pm 0.10$ basally and $4.94 \pm 0.10 \mathrm{mmol} /$ liter during insulin infusion. The coefficient of variation of arterial blood glucose concentration was $<4 \%$ throughout the insulin infusion. Basal plasma insulin tended to be higher in NIDDM (12.8 1.5 $\mathrm{mU} / \mathrm{liter})$ than in the controls $(9.6 \pm 0.8)$, but this was not significant $(P=0.07)$. Insulin concentrations were equivalent during the last $30 \mathrm{~min}$ of insulin infusion $(78 \pm 3$ vs. $77 \pm 3$ $\mathrm{mU} /$ liter, NS) in NIDDM and control subjects. Basal leg blood flow was lower in the NIDDM subjects $(5.34 \pm 0.18$ $\mathrm{ml} /[\mathrm{min} \cdot 100 \mathrm{ml}$ tissue]) than in the controls $(6.04 \pm 0.28, P$ $<0.05$ ), and did not change significantly in either group during the insulin infusion. The rate of glucose infusion required to maintain euglycemia in the nondiabetics during insulin infusion was $234 \pm 16 \mathrm{mg} /\left(\mathrm{m}^{2} \cdot \mathrm{min}\right)$, which was not significantly different from that required to maintain hyperglycemia in the subjects with NIDDM $\left(330 \pm 48 \mathrm{mg} /\left[\mathrm{m}^{2} \cdot \mathrm{min}\right]\right)$.

Leg glucose uptake (Table II). Basal leg glucose uptake was similar in controls and NIDDM $(0.57 \pm 0.06$ vs. $0.73 \pm 0.16$ $\mu \mathrm{mol} /[\mathrm{min} \cdot 100 \mathrm{ml}$ tissue], respectively). During infusion of insulin, the time course of stimulation of leg glucose uptake was similar in both groups and steady-state conditions were attained by $180 \mathrm{~min}$. During the final $30 \mathrm{~min}$ of insulin infusion, leg glucose uptake was $5.64 \pm 0.37 \mu \mathrm{mol} /(\min \cdot 100 \mathrm{ml}$ tissue) in controls and $8.06 \pm 1.41 \mu \mathrm{mol} /(\mathrm{min} \cdot 100 \mathrm{ml}$ tissue $)$ in NIDDM. Due to significantly greater variability among subjects with NIDDM ( $F$-test on ratio of variances, $P<0.01$ ), the difference in leg glucose uptake between NIDDM and controls was not significant $(P=0.06)$. Leg glucose clearance was reduced in NIDDM during the final 30 min of insulin infusion $(0.74 \pm 0.13$ vs. $1.14 \pm 0.07 \mathrm{ml} /[\mathrm{min} \cdot 100 \mathrm{ml}$ tissue], $P<0.01)$. Neither basal nor insulin-stimulated leg glucose uptake was correlated with fasting blood glucose in the diabetic subjects. Rates of exogenous glucose infusion were correlated with rates of leg glucose uptake during insulin infusion in NIDDM $(r$ $=0.83, P=0.001)$ and in controls $(r=0.68, P=0.005)$.

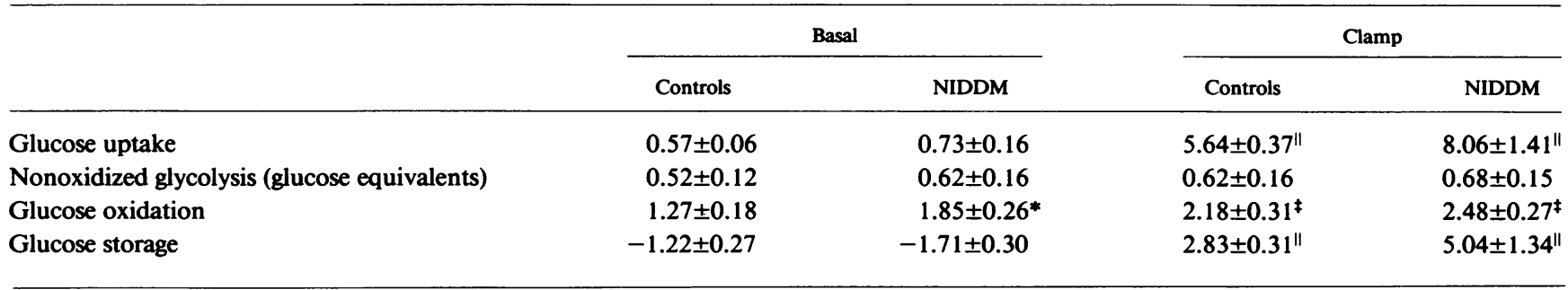

All rates are expressed in terms of $\mu \mathrm{mol}$ glucose/min per $100 \mathrm{ml} \mathrm{leg}$ tissue. Nonoxidized glycolysis is the sum of net alanine plus lactate balance expressed in glucose equivalents. ${ }^{*} P<0.05$ Diabetics vs. Controls; ${ }^{\ddagger} P<0.05$ and $" P<0.01$, Basal vs. insulin infusion. 


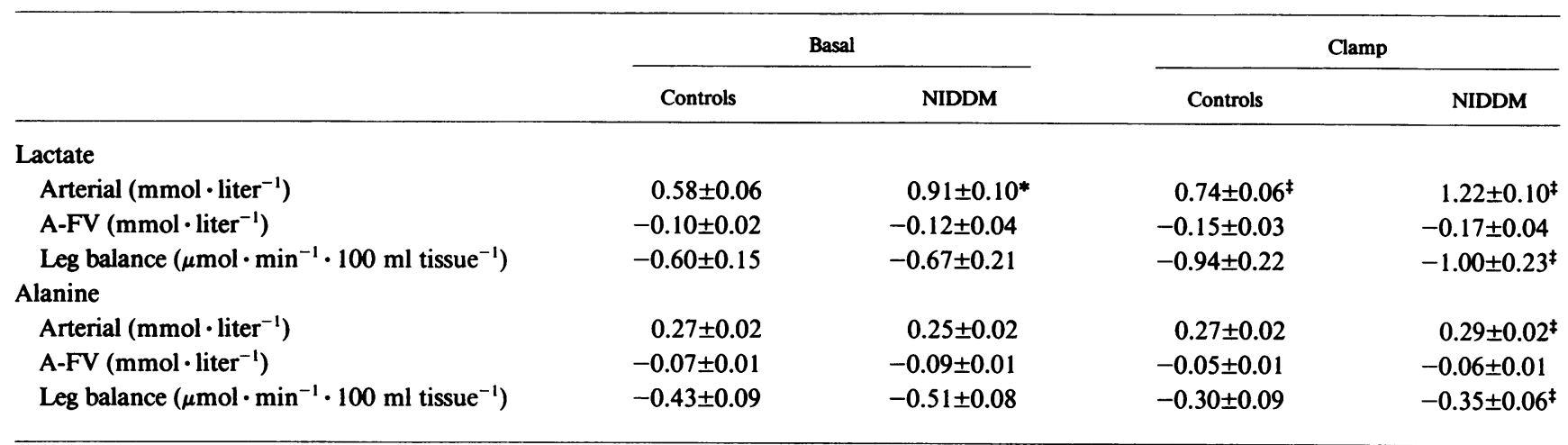

Data are given as means \pm SEM. ${ }^{*} P<0.01$ vs. control values; ${ }^{\ddagger} P<0.05$ vs. basal values.

Leg nonoxidized glycolysis (lactate and alanine balance, Tables II and III). Basally, arterial blood lactate was significantly higher in NIDDM subjects than euglycemic controls (Table III). During insulin infusion, arterial lactate increased in controls $(0.58 \pm 0.06$ to $0.74 \pm 0.06 \mathrm{mmol} / \mathrm{liter}, P<0.01)$ and in NIDDM $(0.91 \pm 0.10$ to $1.22 \pm 0.10 \mathrm{mmol} / \mathrm{liter}, P<0.01)$. Despite increased arterial lactate concentrations in NIDDM, release of lactate by the leg was equivalent in the two groups basally $(0.60 \pm 0.15$ vs. $0.67 \pm 0.21 \mu \mathrm{mol} /[\mathrm{min} \cdot 100 \mathrm{ml}$ tissue], controls vs. NIDDM), and during the final $30 \mathrm{~min}$ of insulin infusion $(0.94 \pm 0.22$ vs. $1.00 \pm 0.23 \mu \mathrm{mol} /[\mathrm{min} \cdot 100 \mathrm{ml}$ tissue]).

Arterial blood alanine concentrations (Table III) were equivalent in controls and diabetics and did not change during insulin infusion in controls $(0.27 \pm 0.02$ vs. $0.27 \pm 0.02 \mathrm{mmol} /$ liter), whereas in NIDDM arterial alanine increased modestly $(0.25 \pm 0.02$ vs. $0.29 \pm 0.02 \mathrm{mmol} / \mathrm{liter}, P<0.05)$. Basally, there was a net release of alanine by leg tissue, which was similar in controls and in NIDDM. Infusion of insulin decreased net alanine release by leg in controls $(0.43 \pm 0.09$ to $0.30 \pm 0.09$ $\mu \mathrm{mol} /[\mathrm{min} \cdot 100 \mathrm{ml}$ tissue], $P<0.05)$ and in NIDDM $(0.51 \pm 0.08$ to $0.35 \pm 0.06 \mu \mathrm{mol} /[\mathrm{min} \cdot 100 \mathrm{ml}$ tissue], $P$ $<0.05$ ).

In controls and diabetics, infusion of insulin produced similar increases in net release of lactate and decreases in net release of alanine by the leg (Table III). The increment in arterial blood lactate between basal and steady-state levels during the insulin infusion was correlated with the increment in arterial alanine $(r=0.86, P<0.01)$, as was the increment in arterial lactate and the rate of exogenous glucose infusion $(r$ $=0.64, P<0.05$ ). However, there was no correlation between the changes in net release of lactate by leg tissues during insulin infusion and increments in arterial lactate $(r=0.025$, NS).

The sum of leg net lactate and alanine release can be considered to be an estimate of the rate of nonoxidized glycolysis (22). For this purpose, lactate and alanine release were expressed in terms of glucose equivalents ( $1 \mathrm{~mol}$ glucose $=2 \mathrm{~mol}$ lactate or alanine). As seen in Table II, nonoxidized glycolysis increased slightly but not significantly in controls $(0.52 \pm 0.12$ vs. $0.62 \pm 0.16 \mu \mathrm{mol} /[\mathrm{min} \cdot 100 \mathrm{ml}$ tissue], basal vs. insulin infusion) and NIDDM (0.62 \pm 0.16 vs. $0.68 \pm 0.15 \mu \mathrm{mol} /[\mathrm{min}$. $100 \mathrm{ml}$ tissue]). There were no differences between the groups.

Leg glucose and lipid oxidation (local indirect calorimetry, Figs. 1-3, Tables II and IV. Data concerning leg $\mathrm{O}_{2}$ consumption and $\mathrm{CO}_{2}$ release are given in Table IV. Arterial blood $\mathrm{O}_{2}$ and $\mathrm{CO}_{2}$ content were similar in controls and NIDDM. Femoral venous (FV) oxygen content was lower in NIDDM than in controls due to reduced oxyhemoglobin saturation level in NIDDM basally $(61.5 \pm 1.8 \%$ vs. $67.5 \pm 1.4 \%, P<0.05)$ and during insulin infusion $(58.6 \pm 2.0 \%$ vs. $66.4 \pm 2.4 \%)$. The resulting increased basal A-FV difference for $\mathrm{O}_{2}$ in NIDDM was offset by reduced leg blood flow such that basal leg oxygen consumption was equivalent to that in controls $(15.36 \pm 0.80$ vs. $15.31 \pm 0.85 \mu \mathrm{mol} /[\mathrm{min} \cdot 100 \mathrm{ml}$ tissue], controls vs. diabetics, respectively). Basal $\mathrm{CO}_{2}$ production by the leg was greater in diabetics than in controls $(14.03 \pm 0.87$ vs. $13.0 \pm 0.82$ $\mu \mathrm{mol} /[\mathrm{min} \cdot 100 \mathrm{ml}$ tissue]), which resulted in a significantly higher value for the basal RQ across the leg in NIDDM $(0.92 \pm 0.03$ vs. $0.84 \pm 0.02, P<0.01)$, as can be seen in Fig. 1 .

Oxygen consumption by leg tissue during the final $30 \mathrm{~min}$ of insulin infusion did not change compared with the basal rate in controls $(15.36 \pm 0.80$ vs. $15.24 \pm 1.00 \mu \mathrm{mol} /[\mathrm{min} \cdot 100$ $\mathrm{ml}$ tissue]) or diabetics $(15.31 \pm 0.85$ vs. $16.71 \pm 0.89)$. However, production of $\mathrm{CO}_{2}$ by leg tissues increased during infusion of insulin and glucose in controls $(13.0 \pm 0.82$ vs. $14.58 \pm 0.80$ $\mu \mathrm{mol} /[\mathrm{min} \cdot 100 \mathrm{ml}$ tissue]), and in NIDDM (14.03 $\pm 0.87 \mathrm{vs}$. $16.14 \pm 0.99 \mu \mathrm{mol} /[\mathrm{min} \cdot 100 \mathrm{ml}$ tissue]). Because of the increased $\mathrm{CO}_{2}$ production during insulin infusion, the $R Q$ across the leg tissue increased significantly in controls (from $0.84 \pm 0.02$ to $0.97 \pm 0.02, P<0.01$ ), but the increment in RQ in NIDDM $(0.92 \pm 0.03$ vs. $0.96 \pm 0.02)$ was not significant (see Fig. 1).

Rates of gas exchange across the leg were used to calculate rates of glucose and lipid oxidation by the leg (Table II, Fig. 2). As expected from the elevated basal $R Q$ in patients with NIDDM, basal glucose oxidation by leg tissues was increased in NIDDM compared with controls $(1.85 \pm 0.26$ vs. $1.27 \pm 0.18$ $\mu \mathrm{mol} /[\mathrm{min} \cdot 100 \mathrm{ml}$ tissue], $P<0.05$ ) and rates of lipid oxida-

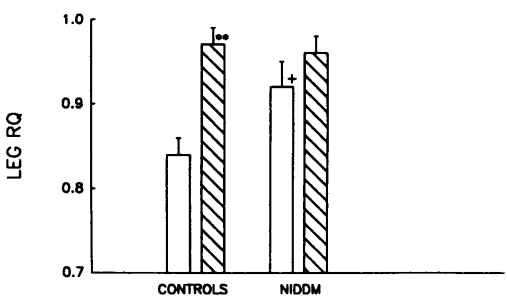

Figure 1. Basal (open bars) and insulin-stimulated (hatched bars) leg RQ in control and NIDDM subjects. RQ is calculated as $\mathrm{VCO}_{2} /$ $\mathrm{VO}_{2}$, where $\mathrm{VCO}_{2}$ and $\mathrm{VO}_{2}$ are determined as the $\mathrm{A}-\mathrm{V}$ differences in blood $\mathrm{CO}_{2}$ and $\mathrm{O}_{2}$ content multiplied by blood flow. ${ }^{* * P}<0.01$ insulin vs. basal; $+P<0.05$ controls vs. diabetics. 

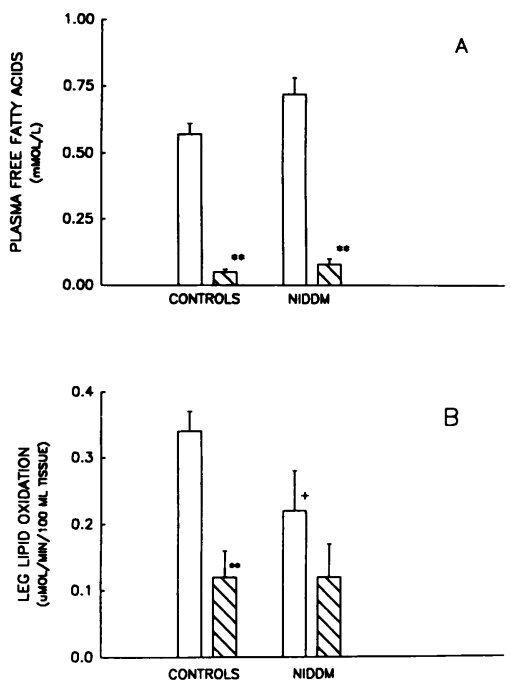

Figure 2. Plasma free fatty acid concentrations $(A)$ and leg lipid oxidation $(B)$ in control and NIDDM subjects. Basal data are given as open bars; insulin-suppressed data as hatched bars. ${ }^{* *} P<0.01$ insulin vs. basal; $+P<0.05$ controls vs. diabetics. tion were lower in NIDDM $(0.22 \pm 0.06$ vs. $0.34 \pm 0.03$ $\mu \mathrm{mol} /[\mathrm{min} \cdot 100 \mathrm{ml}$ tissue], $P<0.05)$. Insulin infusion increased the rates of glucose oxidation by leg tissue significantly above basal rates in both groups, and insulin-stimulated leg glucose oxidation did not differ significantly between NIDDM and controls $(2.48 \pm 0.27$ vs. $2.18 \pm 0.12 \mu \mathrm{mol} /[\mathrm{min} \cdot 100 \mathrm{ml}$ tissue], respectively). In controls, there was a significant decrease in leg lipid oxidation during the clamp (from $0.34 \pm 0.03$ to $0.12 \pm 0.04 \mu \mathrm{mol} /[\mathrm{min} \cdot 100 \mathrm{ml}$ tissue], $P<0.05$ ), but the decrease in leg lipid oxidation in NIDDM was not significant. Despite lower lipid oxidation rates, plasma FFA levels (Fig. 2) were higher in NIDDM during the basal period $(0.72 \pm 0.06 \mathrm{vs}$. $0.57 \pm 0.04 \mathrm{mmol} / \mathrm{liter}, P<0.05)$ and were suppressed by insulin infusion to equivalent levels $(0.08 \pm 0.02$ vs. $0.05 \pm 0.01$ $\mathrm{mmol} /$ liter, NIDDM vs. controls, respectively). In control subjects, insulin stimulation of glucose oxidation was correlated with that of insulin-stimulation of release of glycolytic products (Fig. 3; $r=0.79, P<0.01$ ), but there was no such correlation in the diabetics.
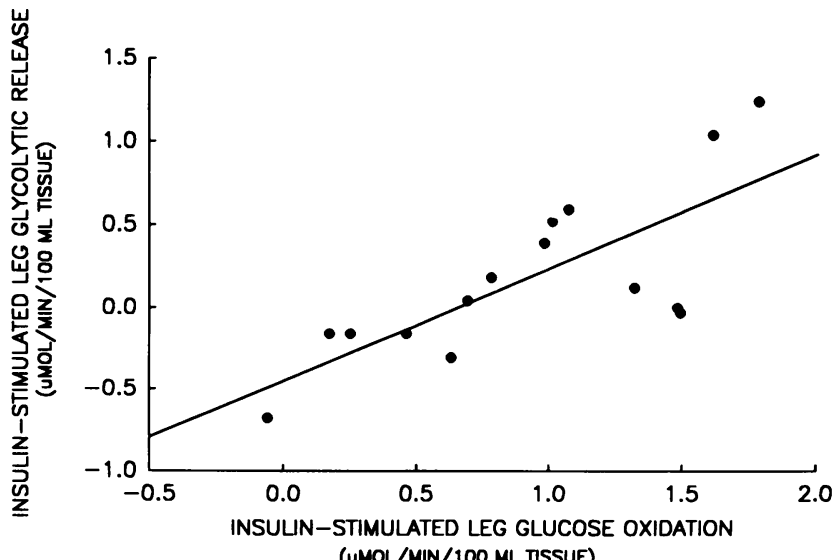

Figure 3. Relationship between insulin-stimulated leg glucose oxidation and release of glycolytic products in nondiabetic subjects. Data are expressed as insulin-stimulated differences from basal rates of leg glucose oxidation or nonoxidized glycolysis. $r=0.79 ; P<0.01$.
Leg glucose storage (Table II). Rates of leg glucose uptake, leg nonoxidized glycolysis, and leg glucose oxidation were used to calculate net leg glucose storage. In diabetics and controls during postabsorptive conditions, leg glucose oxidation was more than double the rate of leg glucose uptake, and net release of lactate plus alanine was equivalent to leg glucose uptake. As a consequence, there was a negative rate of net glucose storage (interpreted as glycogenolysis) during post absorptive conditions in controls and NIDDM $(-1.22 \pm 0.27$ vs. $-1.71 \pm 0.30 \mu \mathrm{mol} /[\mathrm{min} \cdot 100 \mathrm{ml}$ tissue], NS). During infusion of insulin, the rate of leg glucose storage increased in both groups $(5.04 \pm 1.34$ vs. $2.83 \pm 0.31 \mu \mathrm{mol} /[\mathrm{min} \cdot 100 \mathrm{ml}$ tissue], diabetics vs. controls), although the values were not significantly different due to variability in leg glucose storage rates in NIDDM.

Relationship between activities of muscle enzymes and leg metabolic pathways (Tables V and VI, and Fig. 4). Under basal conditions, glycogen synthase activity at 0.1 and $10 \mathrm{mmol} / \mathrm{liter}$ G6P in diabetics did not differ from control values. In both groups, infusion of insulin resulted in significant stimulation of GS activity assayed at $0.1 \mathrm{mmol} /$ liter G6P, and this stimulation did not differ from that observed in controls $(2.82 \pm 0.43$ vs. $3.05 \pm 0.39 \mathrm{nmol} /[\mathrm{min} \cdot \mathrm{mg}$ ], controls vs. NIDDM). Insulin infusion did not increase GS activity assayed with $10 \mathrm{mmol} /$ liter. As a result, infusion of insulin-stimulated GS $_{\mathrm{Fv}}$ (Table IV) in controls (from $0.272 \pm 0.047$ to $0.391 \pm 0.046, P<0.001$ ) and subjects with NIDDM (from $0.322 \pm 0.041$ to $0.484 \pm 0.054, P<0.001)$. $\mathrm{GS}_{\mathrm{Fv}}$ during insulin infusion in subjects with NIDDM was not statistically greater than control values, nor was the increment between basal and insulin-stimulated $\mathrm{GS}_{\mathrm{Fv}}(0.117 \pm 0.018$ vs. $0.161 \pm 0.022$, controls vs. NIDDM, NS).

The relationships between insulin activation of $\mathrm{GS}_{\mathrm{FV}}$ and insulin stimulation of leg glucose uptake and storage in subjects with NIDDM are shown in Fig. 4, $a$ and $b$, respectively. Insulin stimulation of $\mathrm{GS}_{\mathrm{Fv}}$ was correlated with insulin stimulation of leg glucose uptake $(r=0.651, P<0.01)$ and leg glucose storage $(r=0.592, P<0.02)$. There were no significant correlations in the control subjects between insulin stimulation of glycogen synthase and leg glucose uptake $(r=0.05)$ or leg glucose storage $(r=-0.133)$.

Basally, $\mathrm{PDH}_{\mathrm{a}}$ (Table VI) was similar in diabetics and controls $(1.06 \pm 0.15$ vs. $0.93 \pm 0.147 \mathrm{nmol} /[\mathrm{min} \cdot \mathrm{mg}$ protein] $)$, and although $\mathrm{PDH}_{\mathrm{t}}$ was higher in controls, this difference was not significant $(2.86 \pm 0.38$ vs. $2.44 \pm 0.37 \mathrm{nmol} /[\mathrm{min} \cdot \mathrm{mg}])$. Basal $\mathrm{PDH}_{\mathrm{Fv}}$ in diabetics was significantly greater than controls $(0.467 \pm 0.068$ vs. $0.330 \pm 0.022, P<0.05)$. Insulin infusion did not significantly increase $\mathrm{PDH}_{\mathrm{a}}$ or $\mathrm{PDH}_{\mathrm{t}}$ in either the diabetics or the controls. When diabetics and controls were considered together, basal muscle $\mathrm{PDH}_{\mathrm{Fv}}$ and basal leg glucose oxidation were significantly, although weakly, correlated $(r=0.505, P$ $<0.01$; see Fig. 10), as were $\mathrm{PDH}_{\mathrm{a}}$ and basal leg glucose oxidation $(r=0.393, P<0.05)$.

Glycogen synthase and PDH activity in NIDDM subjects during euglycemia (Table VII). In four subjects with NIDDM, GS and PDH were assayed in biopsies taken under euglycemic conditions after slow overnight insulin infusion (4-12 $\left.\mathrm{mU} /\left[\mathrm{m}^{2} \cdot \mathrm{min}\right]\right)$ and then after four hours of infusion of insulin at a rate of $40 \mathrm{mU} /\left(\mathrm{m}^{2} \cdot \mathrm{min}\right)$ while euglycemia was maintained. After overnight insulin, the plasma insulin concentration was $17 \pm 4 \mathrm{mU} / \mathrm{ml}$ in these subjects; during the 40 $\mathrm{mU} /\left(\mathrm{m}^{2} \cdot \mathrm{min}\right)$ insulin infusion, plasma insulin reached a 


\begin{tabular}{|c|c|c|c|c|}
\hline & \multicolumn{2}{|c|}{ Basal } & \multicolumn{2}{|c|}{ Clamp } \\
\hline Arterial (mmol/liter) & $8.63 \pm 0.15$ & $8.56 \pm 0.14$ & $8.30 \pm 0.16$ & $8.16 \pm 0.18$ \\
\hline A-FV (mmol/liter) & $2.56 \pm 0.11$ & $2.89 \pm 0.16$ & $2.58 \pm 0.20$ & $3.11 \pm 0.17$ \\
\hline $\mathrm{VO}_{2}$ & $15.36 \pm 0.80$ & $15.31 \pm 0.85$ & $15.24 \pm 1.00$ & $16.71 \pm 0.89$ \\
\hline \multicolumn{5}{|l|}{ Carbon diaxide } \\
\hline Arterial (mmol/liter) & $21.99 \pm 0.28$ & $22.06 \pm 0.37$ & $21.46 \pm 0.32$ & $21.61 \pm 0.42$ \\
\hline A-FV (mmol/liter) & $-2.17 \pm 0.12$ & $-2.65 \pm 0.17^{*}$ & $-2.47 \pm 0.17^{\ddagger}$ & $-3.01 \pm 0.19^{\ddagger}$ \\
\hline $\mathrm{VCO}_{2}$ & $13.00 \pm 0.82$ & $14.03 \pm 0.87$ & $14.58 \pm 0.80^{\ddagger}$ & $16.14 \pm 0.99$ \\
\hline
\end{tabular}

Data are given as means \pm SEM. ${ }^{*} P<0.05$ Control vs. NIDDM $;{ }^{\ddagger} P<0.01$ Clamp vs. basal.

steady-state plateau of $67 \pm 4 \mathrm{mU} / \mathrm{ml}$, which was not different from those insulin concentrations achieved during insulin infusion at hyperglycemia.

Basal GS activity and $\mathrm{GS}_{\mathrm{Fv}}$ were significantly decreased by $75 \%$ during euglycemia as compared with hyperglycemia (Table VII). Muscle GS activity and $\mathrm{GS}_{\mathrm{Fv}}$ were similarly decreased at euglycemia during insulin infusion. In like fashion, overnight euglycemia resulted in a $50-60 \%$ decrease in muscle $\mathrm{PDH}_{\mathrm{a}}$ basally and during insulin infusion. Unlike the case for GS, though, total PDH activity $\left(\mathrm{PDH}_{\mathrm{t}}\right)$ was also decreased during euglycemia to a comparable extent as was $\mathrm{PDH}_{\mathrm{a}}$. Therefore, $\mathrm{PDH}_{\mathrm{Fv}}$ during euglycemia was not different to that during hyperglycemia (Table VII).

\section{Discussion}

Critical to understanding the mechanism responsible for skeletal muscle insulin resistance in NIDDM is the question of whether impaired muscle glucose storage and oxidation occur independently of defects in glucose uptake. To address this issue, we used the limb balance technique to compare skeletal muscle glucose oxidation and storage, as well as muscle GS and PDH activities under conditions in which rates of muscle glucose uptake were matched in NIDDM and nondiabetic subjects at equivalent plasma insulin concentrations.

As an initial attempt to achieve comparable rates of muscle glucose uptake in NIDDM and nondiabetic subjects, we studied the NIDDM subjects at their prevailing fasting plasma glucose levels. This was done because Revers et al. had reported that fasting hyperglycemia was able to fully compensate for insulin resistance in NIDDM (6). This approach was successful since, in the present study, we found that basal and insulin-stimulated rates of leg glucose uptake were equivalent in NIDDM subjects studied at their fasting plasma glucose levels and nondiabetic volunteers studied at euglycemia. These results suggest that fasting hyperglycemia in a patient with NIDDM is the equilibrium point at which glucose production by the liver normalizes the rate of muscle glucose uptake. Although rates of systemic and leg glucose uptake were equivalent, glucose clearance systemically and across the leg was reduced in the NIDDM subjects. Thus, hyperglycemia in
NIDDM subjects did not completely eliminate insulin resistance. In both groups of subjects, leg glucose uptake was strongly correlated with systemic glucose disposal, accounting for nearly three-quarters of the variability in insulin-stimulated glucose disposal. Therefore, muscle is a key tissue in which compensation for insulin resistance by hyperglycemia takes place, and the prevailing fasting hyperglycemia of an individual with NIDDM is sufficient for this phenomenon to occur.

Despite normal basal leg glucose uptake, there were significant abnormalities in basal muscle glucose and lipid metabolism in the subjects with NIDDM. The basal rate of leg glucose oxidation was significantly greater in the diabetics, and this was associated with significantly increased muscle PDH activity. This increase in basal leg glucose oxidation in NIDDM occurred in spite of significantly greater plasma FFA concentrations, which suggests that there may be an abnormality in FFA clearance by muscle in NIDDM. Decreased systemic clearance of FFA in subjects with NIDDM has been reported (32). Although the extent to which muscle contributes to this defect is unknown, it may be significant, since muscle in normal subjects predominantly uses FFA as its oxidative substrate. Parenthetically, decreased use of FFA by muscle could lead to increased plasma FFA levels and increased hepatic lipid oxidation, which could in turn lead to increased hepatic glucose production (33) and be a mechanism that links defects in skeletal muscle with those in liver in NIDDM. Such an increase in hepatic lipid oxidation could offset the decrease in

Table V. Muscle Glycogen Synthase Activities

\begin{tabular}{lccccc}
\hline & \multicolumn{2}{c}{ Basal } & & \multicolumn{2}{c}{ Clamp } \\
\cline { 2 - 3 } \cline { 5 - 6 } $\begin{array}{l}\text { Glycogen } \\
\text { synthase activity }\end{array}$ & Controls & NIDDM & & Controls & NIDDM \\
\hline & & & & \\
& & & & & \\
$(0.1 \mathrm{mM}$ G6P) & $1.59 \pm 0.29$ & $2.15 \pm 0.35$ & & $2.82 \pm 0.43^{*}$ & $3.05 \pm 0.39^{*}$ \\
$(10 \mathrm{mM}$ G6P) & $6.14 \pm 0.62$ & $8.03 \pm 1.49$ & & $7.21 \pm 0.67$ & $7.85 \pm 1.15$ \\
$\left(\mathrm{GS}_{\mathrm{Fv}}\right)$ & $0.272 \pm 0.047$ & $0.322 \pm 0.041$ & & $0.391 \pm 0.046^{*}$ & $0.484 \pm 0.054^{*}$
\end{tabular}

Data are given as means \pm SEM in units of $\mathrm{nmol}{ }^{14} \mathrm{C}$-UDPG converted to

$\left[{ }^{14} \mathrm{C}\right]$ glycogen $/ \mathrm{min}$ per $\mathrm{mg}$ extract protein. ${ }^{*} P<0.001$ vs. basal values. 
Table VI. Muscle PDH Activities

\begin{tabular}{lccccc}
\hline & \multicolumn{2}{c}{ Basal } & & \multicolumn{2}{c}{ Clamp } \\
\cline { 2 - 3 } \cline { 5 - 6 } & Controls & NIDDM & & Controls & NIDDM \\
\hline $\mathrm{PDH}_{\mathrm{a}}$ & $0.93 \pm 0.15$ & $1.06 \pm 0.15$ & & $1.00 \pm 0.13$ & $1.19 \pm 0.16$ \\
$\mathrm{PDH}_{\mathrm{t}}$ & $2.86 \pm 0.38$ & $2.44 \pm 0.37$ & & $2.90 \pm 0.35$ & $2.95 \pm 0.33$ \\
$\mathrm{PDH}_{\mathrm{FV}}$ & $0.330 \pm 0.022$ & $0.467 \pm 0.068^{*}$ & & $0.365 \pm 0.043$ & $0.417 \pm 0.055$
\end{tabular}

Data are given as means \pm SEM in units of nmol $1-\left[{ }^{14} \mathrm{C}\right]$ pyruvate converted to ${ }^{14} \mathrm{CO}_{2} / \mathrm{min}$ per $\mathrm{mg}$ extract protein. ${ }^{*} P<0.05$ vs. control values.

muscle lipid oxidation, resulting in unchanged or even increased systemic lipid oxidation in NIDDM. Finally, even though muscle glucose oxidation was increased, which suggests increased glycolysis, under basal conditions in NIDDM release of glycolytic products from the leg was normal. This is consistent with the observed increase in $\mathrm{PDH}_{\mathrm{Fv}}$ in that group. In spite of this, arterial lactate levels were greater than in controls, implying that increased blood lactate in NIDDM does not come from muscle.
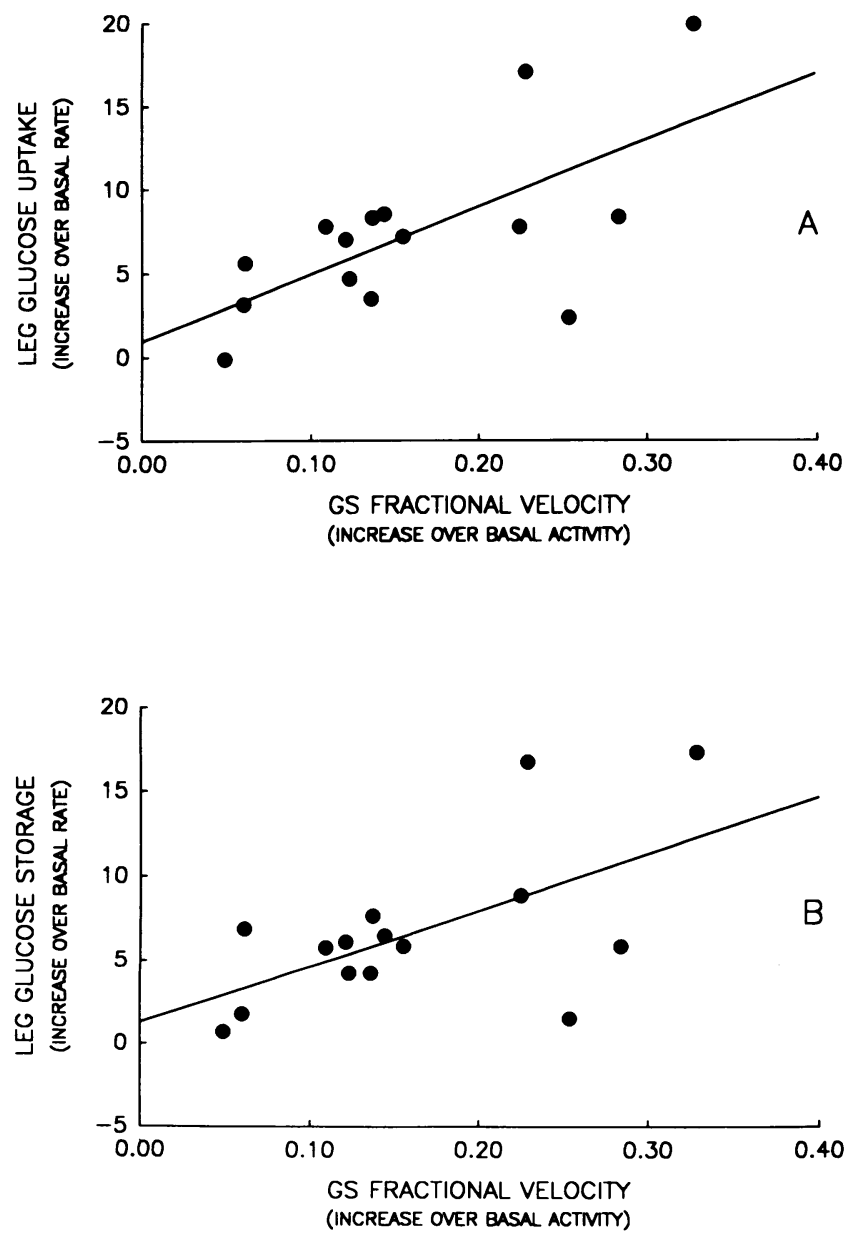

Figure 4. Relationships between insulin stimulation of glycogen synthase $\left(\mathrm{GS}_{\mathrm{FV}}\right)$ and leg glucose uptake $(A)(r=0.651, P<0.01)$, and storage $(B)(r=0.592, P<0.02)$ in fifteen subjects with NIDDM.
Having successfully attained equivalent rates of insulinstimulated muscle glucose uptake in NIDDM and nondiabetic subjects, it was possible to assess whether normalization of glucose uptake compensated for intracellular pathways of glucose metabolism which are decreased when glucose uptake is reduced. If this were the case, it would provide evidence that impaired muscle glucose oxidation and storage in NIDDM are secondary to reduced muscle glucose uptake.

In contrast to the abnormalities found in leg glucose metabolism in NIDDM subjects studied under basal conditions, leg glucose, storage, oxidation, and release of glycolytic products proceeded at normal rates in NIDDM subjects studied when their fasting hyperglycemia was maintained during an insulin infusion. It could be concluded from this that the defect in insulin-stimulated glucose metabolism in muscle occurs at a point that is proximal to all the pathways studied. A likely candidate for the step responsible for this defect is glucose transport. The simplest explanation for the phenomena observed in the present study is that, in NIDDM, hyperglycemia normalizes insulin-stimulated glucose uptake by mass action. Normalization of flux of glucose into the cell would then result in normal rates of intracellular glucose metabolism. A similar explanation for muscle insulin resistance in patients with insulin dependent diabetes has recently been put forth (34).

However, these findings do not exclude the possibility that hyperglycemia in NIDDM normalizes leg glucose metabolism by means of direct or indirect effects on muscle GS and PDH. This study provides some evidence that is consistent with this idea. We found that hyperglycemia normalized muscle GS and PDH activities in NIDDM subjects who had a profound defect in the activity of this enzyme when they were studied after being rendered euglycemic by an overnight insulin infusion. One interpretation of these data is that hyperglycemia increased glucose transport by mass action, resulting in increased intracellular concentrations of effectors of GS phosphatase (35, such as G6P) or PDH phosphatase (such as pyruvate), which could result in increased activities of GS and PDH through covalent modification. The normalized GS and PDH activities could then have participated at least in part in normalization of insulin-stimulated muscle glucose storage and oxidation. This effect may be limited to NIDDM, since hyperglycemia only minimally stimulates muscle glycogen synthase in nondiabetic controls (36).

These findings in subjects with NIDDM who were studied while hyperglycemic, differ significantly from those recently reported by Thorburn et al. (7), who reported decreased insulin-stimulated systemic glucose oxidation and muscle glycogen synthase activity, but paradoxically increased systemic glucose storage and elevated plasma lactate concentrations. They concluded from this that, despite normal rates of systemic glucose disposal, muscle glucose metabolism was not normalized, and attributed the increased plasma lactate concentration in NIDDM to increased muscle lactate release. These findings indicate that matching leg glucose uptake to control values by maintaining fasting hyperglycemia normalizes muscle glucose oxidation and storage in NIDDM, and that increased blood lactate concentrations in the diabetics do not come from muscle. The differences between these results and those of Thorburn et al. (7) most likely result from differences in study design and subject selection. In that study, in order to normalize glucose disposal, plasma glucose had to be increased to a mean of $20 \mathrm{mmol} / \mathrm{liter}$, with some subjects being studied at a 
Table VII. Muscle Glycogen Synthase and PDH Activities During Euglycemia Compared with Hyperglycemia in NIDDM

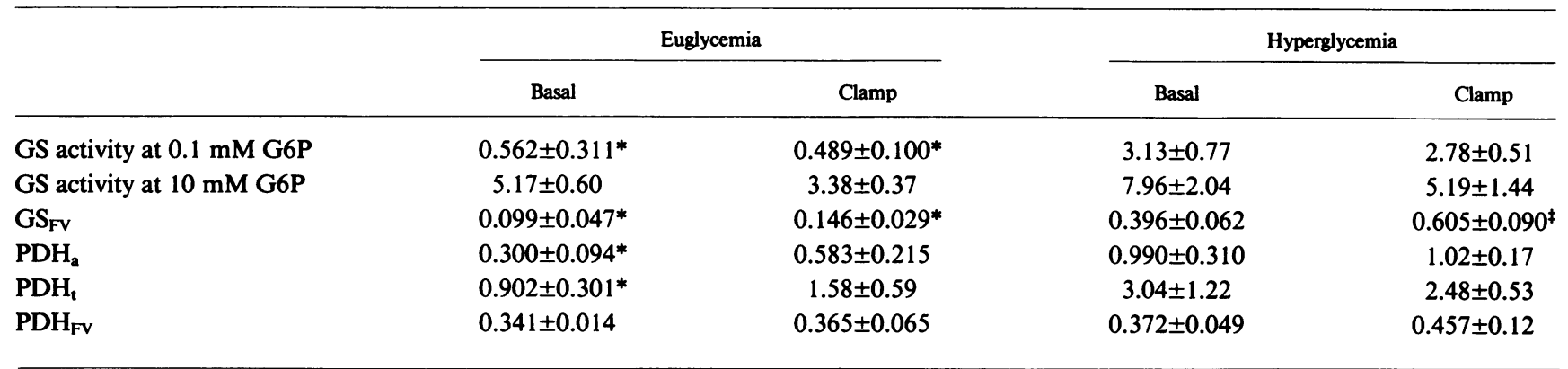

Data are given as means $\pm \mathrm{SEM}$; units are $\mathrm{nmol} / \mathrm{min} \cdot \mathrm{mg}$, as described in legends to Tables IV and $\mathrm{V}$. ${ }^{*} P<0.05$ less than values during hyperglycemia; ${ }^{\ddagger} P<0.05$ greater than basal values.

plasma glucose concentration as high as $30 \mathrm{mmol} / \mathrm{liter}$. The increase in hyperglycemia necessary to match glucose disposal rates to controls was probably due to the fact that the nondiabetic control subjects in the Thorburn study appear to be extremely insulin sensitive compared with those in this study and those used by Revers et al. The reasons for the disparity in insulin sensitivity between the control subjects of Thorburn et al. and those in this study are not readily apparent. Nevertheless, at such high glucose concentrations in the NIDDM subjects, significant uptake and metabolism of glucose (including glycogen deposition and glycolysis) must have occurred in the liver and splanchnic bed (9-17). These tissues are likely to be the sources of the increased plasma lactate concentrations as well as much of the increase in systemic nonoxidative glucose metabolism they observed in the diabetics. Under such conditions, it is not surprising that muscle glycogen synthase activity did not reflect systemic nonoxidative glucose metabolism. Therefore, under conditions of hyperinsulinemia and hyperglycemia, inferences made about muscle from knowledge of systemic glucose metabolism must be made judiciously.

These findings should not be interpreted to mean that in daily life hyperglycemia is somehow beneficial for the patient with NIDDM. The conclusions apply only to conditions of steady-state plasma insulin concentrations matched to controls. After a meal, the pattern of plasma insulin levels in the diabetic will be different than the nondiabetic, so there may not be complete normalization of the pathways of skeletal muscle glucose metabolism, to the extent this depends on insulin concentration. Nevertheless, this study provides data that is useful in determining the biochemical site of insulin resistance.

In conclusion, our results show that basal muscle glucose oxidation is increased in NIDDM in spite of increased plasma FFA levels, suggesting that there is a defect in utilization of FFA by muscle in NIDDM. Further studies will be required to determine whether such a defect in FFA clearance exists as well as what effects it might have on systemic metabolism. Our results also indicate that, during insulin stimulation, maintenance of prevailing hyperglycemia in NIDDM subjects is sufficient to normalize muscle glucose uptake, the oxidative and nonoxidative pathways of muscle glucose metabolism, and muscle glycogen synthase and PDH activities. These findings are consistent with a mechanism whereby fasting hyperglycemia increases until uptake of glucose by muscle is normalized. Once inside muscle cells, glucose is then distributed normally to glycogen formation and glucose oxidation, possibly via nor- malization of glycogen synthase and PDH activities by hyperglycemia.

\section{Acknowledgments}

The expert technical assistance of $\mathbf{L}$. Weiss, J. Finlayson, and R. Thorne, and the nursing staff of the GCRC is gratefully acknowledged. J. Smith and G. Gutkowski provided excellent editorial assistance. We also wish to thank Dr. John Gerich for helpful suggestions.

This work was supported by funds from the American Diabetes Association, Medical Research Service, Department of Veterans Affairs, National Institutes of Health (grant R01-DK-41075), General Clinical Research Center (grant 5 M01-RR-00056), The Pennsylvania Lions, Research To Prevent Blindness, Inc., and The Eye and Ear Institute of Pittsburgh. We also thank the volunteers who participated in this study.

\section{References}

1. DeFronzo, R., D. Deibert, R. Hendler, P. Felig, and V. Soman. 1979. Insulin sensitivity and insulin binding to monocytes in maturity-onset diabetes. J. Clin. Invest. 63:939-946.

2. Kolterman, O., R. Gray, J. Griffin, P. Bernstein, J. Insel, J. Scarlett, and J. Olefsky. 1981. Receptor and postreceptor defects contribute to the insulin resistance in noninsulin-dependent diabetes mellitus. J. Clin. Invest. 68:957-969.

3. Bogardus, C., S. Lillioja, B. V. Howard, G. Reaven, and D. Mott. 1984. Relationships between insulin secretion, insulin action, and fasting plasma glucose concentration in nondiabetic and noninsulindependent diabetic subjects. J. Clin. Invest. 74:1238-1246.

4. Rizza, R., L. Mandarino, and J. Gerich. 1981. Mechanism and significance of insulin resistance in non-insulin-dependent diabetes mellitus. Diabetes. 30:990-995.

5. Bogardus, C., S. Lillioja, K. Stone, and D. Mott. 1984. Correlation between muscle glycogen synthase activity and in vivo insulin action in man. J. Clin. Invest. 73:1185-1190.

6. Revers, R., J. Griffin, and O. Kolterman. 1984. The effect of hyperglycemia on insulin's in vivo effects in type II diabetes mellitus. $J$. Clin. Invest. 73:664-672.

7. Thorburn, A., B. Gumbiner, F. Bulacan, P. Wallace, and R. Henry. 1990. Intracellular glucose oxidation and glycogen synthase activity are reduced in noninsulin-dependent (type II) diabetes independent of impaired glucose uptake. J. Clin. Invest. 85:522-529.

8. DeFronzo, R. A., E. Ferrannini, R. Hendler, P. Felig, and J. Wahren. 1983. Regulation of splanchnic and peripheral glucose uptake by insulin and hyperglycemia in man. Diabetes. 32:35-45.

9. Barrett, E. J., E. Ferrannini, R. Ginsberg, S. Bevilacqua, and R. A. DeFronzo. 1985. Hepatic and extrahepatic splanchnic glucose metabolism in the postabsorptive and glucose fed dog. Metabolism. 34:410-420. 
10. Sacca, L., B. Cicala, B. Trimarco, B. Ungaro, and R. Vigorito. 1982. Differential effects of insulin on splanchnic and peripheral glucose disposal after an intravenous glucose load in man. J. Clin. Invest. 70:117-126.

11. DeFronzo, R. A., E. Ferrannini, R. Hendler, J. Wahren, and P. Felig. 1978. Influence of hyperinsulinemia, hyperglycemia, and the route of glucose administration on splanchnic glucose exchange. Proc. Natl. Acad. Sci. USA. 15:5173-5177.

12. Cherrington, A. D., P. E. Williams, N. Abou-Mourad, W. W. Lacy, K. E. Steiner, and J. E. Liljenquist. 1982. Insulin as a mediator of hepatic glucose uptake in the conscious dog. Am. J. Physiol. 242:E97101.

13. Ishida, T., Z. Chap, J. Chou, R. Lewis, C. Hartley, M. Entman, and J. B. Field. 1983. Differential effects of oral, peripheral intravenous, and intraportal glucose on hepatic glucose uptake and insulin and glucagon extraction in conscious dogs. J. Clin. Invest. 72:590-600.

14. Adkins-Marshall, B., S. Myers, G. Hendrick, P. Williams, K. Triebwasser, B. Floyd, and A. Cherrington. 1990. Interaction between insulin and glucose-delivery route in regulation of net hepatic glucose uptake in conscious dogs. Diabetes. 39:87-95.

15. Bergman, R., J. Bier, and P. Hourigan. 1982. Intraportal glucose infusion matched to oral glucose absorption: lack of evidence for "gut factor" involvement in hepatic glucose storage. Diabetes. 31:2735.

16. Jackson, R., R. Roshania, M. Hawa, B. Sim, and L. DiSilvio. 1986. Impact of glucose ingestion on hepatic and peripheral glucose metabolism in man: an analysis based on simultaneous use of the forearm and double isotope techniques. J. Clin. Endocrinol. \& Metab. 63:541-549.

17. Davis, M., P. Williams, and A. Cherrington. 1984. Effect of a mixed meal on hepatic lactate and gluconeogenic precursor metabolism in dogs. Am. J. Physiol. 247:E362-369.

18. Shulman, G., D. Rothman, T. Jue, P. Stein, R. DeFronzo, and R. Shulman. 1990. Quantitation of muscle glycogen synthesis in normal subjects and subjects with noninsulin-dependent diabetes by ${ }^{13} \mathrm{C}$ nuclear magnetic resonance spectroscopy. N. Engl. J. Med. 322:223228.

19. Yki-Jarvinen, H., A. Young, C. Lamkin, and J. Foley. 1987. Kinetics of glucose disposal in whole body and across the forearm in man. J. Clin. Invest. 79:1713-1719.

20. DeFronzo, R., E. Jacot, E. Maeder, J. Wahren, and J. Felber. 1981. The effect of insulin on the disposal of intravenous glucose. Results from indirect calorimetry and hepatic and femoral venous catheterization. Diabetes. 30:1000-1007.

21. Andres, R., G. Cader, and K. Zierler. 1956. The quantitatively minor role of carbohydrate in oxidative metabolism by skeletal muscle in intact man in the basal state. J. Clin. Invest. 35:671-682.

22. Kelley, D., J. Reilly, T. Veneman, and L. Mandarino. 1990.
The influence of physiologic hyperinsulinemia on skeletal muscle glucose storage, oxidation, and glycolysis in man. Am. J. Physiol. 258:E923-E929.

23. National Diabetes Data Group. Classification and diagnosis of diabetes mellitus and other categories of glucose intolerance. Diabetes. 28:1039-1057.

24. Nyboer, J., P. Murray, and J. Sedersky. 1974. Blood flow indices in amputee and control limbs by mutual electrical impedance plethysmography. Am. Heart J. 87:704-710.

25. Douglas, A., N. Jones, and J. Reed. 1988. Calculation of whole blood $\mathrm{CO}_{2}$ content. J. Appl. Physiol. 65:473-477.

26. Frayn, K. 1984. Calculation of substrate oxidation rates in vivo from gaseous exchange. J. Appl. Physiol: Respirat. Environ. Exercise Physiol. 55:628-634.

27. Gelfand, R., and E. Barrett. 1987. Effect of physiologic hyperinsulinemia on skeletal muscle protein synthesis and breakdown in man. J. Clin. Invest. 80:1-6.

28. Passonneau, J. Lactate. In Methods of Enzymatic Analysis. H. Bergmeyer, editor. Academic Press, New York. 1468-1472.

29. Karl, I., A. Pagliaria, and D. Kipnis. 1972. A microfluorometric enzymatic assay for determination of alanine and pyruvate in plasma and tissue. J. Lab. Clin. Med. 80:434-441.

30. Herbert, V., L. Lau, C. Gottlieb, and S. Bleicher. 1965. Coated charcoal immunoassay of insulin. J. Clin. Endocrinol. \& Metab. 25:1375-1384.

31. Mandarino, L., K. Wright, L. Verity, J. Nichols, J. Bell, O. Kolterman, and H. Beck-Nielsen. 1987. Effects of insulin infusion on human skeletal muscle pyruvate dehydrogenase, phosphofructokinase, and glycogen synthase. J. Clin. Invest. 80:655-663.

32. Taskinen, M.-R., C. Bogardus, A. Kennedy, and B. Howard. 1985. Multiple disturbances of free fatty acid metabolism in noninsulin-dependent diabetes. J. Clin. Invest. 76:637-644.

33. Ferrannini, E., E. Barrett, S. Bevilacqua, and R. DeFronzo. 1983. Effect of fatty acids on glucose production and utilization in man. J. Clin. Invest. 72:1737-1747.

34. Yki-Jarvinen, H., K. Sahlin, J. Ren, and V. Koivisto. 1990. Localization of rate-limiting defect for glucose disposal in skeletal muscle of insulin-resistant Type I diabetic patients. Diabetes. 39:157167.

35. Kida, Y., A. Esposito-Del Puente, C. Bogardus, and D. Mott. 1990. Insulin resistance is associated with reduced fasting and insulinstimulated glycogen synthase phosphatase activity in human skeletal muscle. J. Clin. Invest. 85:476-481.

36. Yki-Jarvinen, H., D. Mott, A. Young, K. Stone, and C. Bogardus. 1987. Regulation of glycogen synthase and phosphorylase activities by glucose and insulin in human skeletal muscle. J. Clin. Invest. 80:95-100. 